\title{
CONTRIBUIÇÕES PARA O ENTENDIMENTO DA OBRA DE MANUEL CORREIA DE ANDRADE: GEOGRAFIA, REGIÃO, ESPAÇO E TERRITÓRIO
}

Prof. Dr. Marcos Aurelio Saquet

Unioeste - Francisco Beltrão

Pesquisador do Cnpq saquetmarcos@hotmail.com

\begin{abstract}
Resumo
Este texto é resultado de nossas pesquisas sobre as abordagens e concepções de território na Geografia brasileira. Estamos estudando obras de autores como Milton Santos, Antonio Carlos Robert Moraes e Manual Correia de Andrade. Neste texto, descrevemos e analisamos algumas obras que julgamos fundamentais deste último autor mencionado, evidenciando sua concepção de Geografia, região, espaço geográfico e território entre 1963 e 1995, elaborada no bojo do movimento de renovação recente da ciência geográfica ocorrido no Brasil, na França e noutros países.

Palavras-chave: Geografia; Região; Espaço; Território.
\end{abstract}

Abstract

This text is a result of our researches about the approaches and conceptions of territory in the Brazilian Geography. We are studying titles of authors as Milton Santos, Antonio Carlos Roberto Moraes and Manuel Correia de Andrade. On this context, we have described some Manuel Correia de Andrade`s Titles that we have considered important, out standing his conception on the core of the movement of recent renew of geographic science happened in Brazil, France and other countries.

Key words: Geography; Region; Space; Territory.

Introdução

Este texto é produto das pesquisas que estamos fazendo inerentes ao projeto de pesquisa intitulado Sobre os conceitos de território e territorialidade: abordagens $e$ 
concepções, financiado pelo Cnpq através de uma bolsa de produtividade em pesquisa ${ }^{1}$. Na primeira fase da pesquisa, evidenciamos obras e autores da Itália e da França, especialmente aqueles que se constituíram em referências internacionais no processo de renovação da geografia a partir dos anos 1960-70, como demonstramos em Saquet (2006 e 2007).

Destacamos autores estrangeiros como Jean Gottmann, Dilles Gileuze, Felix Guattari, Giuseppe Dematteis, Claude Raffestin, Robert Sack, Alberto Magnaghi, Francesco Indovina, Massimo Quaini, Arnaldo Bagnasco, Bertrand Badie, entre outros, revelando aspectos de suas abordagens teórico-metodológicas e os principais elementos considerados na compreensão do território. Ao mesmo tempo, iniciamos o estudo de autores e obras da literatura brasileira, como Octavio Ianni, Milton Santos, Manuel Correia de Andrade, Roberto Lobato Corrêa, Rogério Haesbaert, Ariovaldo Umbelino de Oliveira, Marcelo Lopes de Souza, Eliseu Savério Sposito, Bernardo Mançano Fernandes, entre outros, fazendo, também, uma espécie de auto-reflexão sobre minha trajetória e as concepções de geografia, espaço, território e territorialidade.

Neste momento das pesquisas, estamos aprofundando os estudos sobre a abordagem e concepção de Milton Santos, Antonio Carlos Robert Moraes e Manuel Correia de Andrade, pelo pioneirismo e pela importância em nível internacional e no Brasil. Neste texto, socializamos os principais resultados obtidos sobre a obra de Manuel Correia de Andrade, elaborada num contexto e período de renovação da geografia e de mudanças profundas no mundo.

Manuel Correia de Andrade, nascido em 03 de agosto de 1922, em Pernambuco, formou-se em direito, geografia e história, cursando pós-graduação tanto no Brasil como na França, no Instituto de Altos Estudos da América Latina da Universidade de Paris (196465). Ele foi influenciado por elementos de uma concepção renovada de geografia carregada por fortes traços da abordagem regional efetivada no período 1940-60 sob influência da chamada escola vidaliana.

No entanto, ele também foi influenciado por concepções elaboradas por autores como M. Rochefort, P. Monbeig e O. Dollfus, estudiosos que têm centralidade na construção do

\footnotetext{
${ }^{1}$ Este projeto também contou, no ano de 2008, com o apoio financeiro da Fundação Araucária (PR). Geo UERJ - Ano 12, nº. 21, v. 2, 2º semestre de 2010. www.geouerj.uerj.br/ojs ISSN 1981-9021
} 
arcabouço teórico-metodológico que resultou no entendimento do espaço construído socialmente, além de Jacques Boudeville e François Perroux, um dos principais teóricos sobre os pólos de desenvolvimento econômico. Sua elaboração ocorreu no bojo de mudanças na produção do conhecimento em ciências sociais, tentando acompanhar as transformações socioespaciais profundas ocorridas no pós-1960-70, como a intensificação da degradação ambiental, da expansão urbana, da industrialização em nível internacional, das desigualdades sociais etc., bem como mudanças que aconteceram no nível do pensamento científico e filosófico.

Manuel Correia de Andrade foi envolvido e influenciado por aspectos do movimento de renovação da geografia e de outras ciências, no qual destacam-se autores como Paul Claval, Bernard Kayser, David Harvey, Yves Lacoste, Pierre George, Jean Tricart, Pierre Deffontaines, entre outros. Movimento que gera uma geografia, ou geografias, muito vinculadas à denúncia de processos sociais até então negligenciados, especialmente no que se refere à chamada organização espacial, tanto urbana como rural sob influência da interpretação marxista.

Há um esforço para tentar superar o desinteresse epistemológico pela revisão metodológica e conceitual predominante e para compreender as transformações sociais vigentes na época (Dematteis, 2005; Harvey, 2005; Saquet, 2007; Raffestin, 2008). Movimento disperso envolvendo pesquisadores dos EUA, da Grã-Bretanha, da França, da Suíça, da Itália, entre outros países, como o Brasil, e estudiosos como Manuel Correia de Andrade. "A renovação da Geografia passa pelos esforços de construção conceitual para poder elaborar diversas teorias sem a utilização das quais não se pode ter, aí, progressos reais” (Raffestin, 2008, p.4).

Há uma conjugação de componentes imateriais-materiais que condiciona a emergência de novos componentes na reflexão geográfica a partir, principalmente, de atitudes anti-positivistas presentes em obras e autores que propugnam em favor da fenomenologia ou do materialismo histórico e dialético. Nesta renovação, debate-se conceitos como os de paisagem, região, espaço e território, todos fundamentais para a ciência geográfica. 
Na geografia, nesta transição que se dá a partir dos anos 1950 até o final da década de 1970, busca-se romper e superar a abordagem positivista ou neopositivista muito presentes, por exemplo, na geografia regional francesa realizada até aquele período ou na nova geografia, negligenciando-se o conceito de território em favor da utilização do conceito de região entendido, sucintamente, como um recorte espacial com determinadas características naturais e humanas. Questiona-se e tenta-se superar aquela geografia entendida como ciência dos meios naturais ou ciência das formas da diferenciação espacial (Lacoste, 1974) centrada na dicotomização entre a sociedade e a natureza, eminentemente descritiva e classificatória, mascarando processos contraditórios, conflituais e degradantes.

Na renovação, constroem-se caminhos distintos a partir da tomada de consciência das mudanças necessárias por parte de alguns pensadores: um centrado nos estudos regionais a partir de dados físicos e humanos; outro, de caráter mais geral, pautado na descrição de vastos conjuntos territoriais enfatizando-se aspectos demográficos, econômicos e políticos; outro, com significativa ênfase para os processos históricos (Lacoste, 1974).

No Brasil, a partir dos anos 1970, como já é bem conhecido, na geografia, incorporam-se princípios do materialismo histórico e dialético, especialmente através da atuação acadêmica e científica de professores da USP. Há, evidentemente, outras perspectivas bem significativas que permanecem, como a denominada new geography e a geografia regional feita, por exemplo, por Manuel Correia de Andrade, entre outros pesquisadores que trabalham para tentar explicar as desigualdades regionais historicamente construídas no Brasil.

A geografia regional francesa, que muito influenciou Manuel Correia de Andrade tem, no decorrer do século XX, especialmente até os anos 1960, forte influência de Paul Vidal de La Blache e de seus seguidores, como Emmanuel de Martonne e Albert Demangeon, num esforço para produzir conhecimento geográfico que se contrapunha às abordagens mais gerais de Karl Ritter e Friedrich Ratzel. Das regiões naturais passa-se às regiões econômicas e/ou administrativas, com determinados gêneros de vida. Ganha força, cada vez mais, na geografia, a organização e a diferenciação do espaço geográfico, como compartimento para ser classificado, descrito e explicado. 
Era tarefa do geógrafo delimitar, descrever e explicar as parcelas do espaço, evidenciando as diversidades regionais, como fizera Manuel Correia de Andrade, no Brasil: para ele, principalmente durante os anos 1960-80, a região era uma realidade histórica e administrativa, com pólos de crescimento e determinados recursos naturais. Aos poucos, na França, no Brasil e noutros países, ganham centralidade os elementos humanos e históricos diante dos naturais compreendidos em determinadas áreas. Neste processo de renovação, Manuel Correia de Andrade se destaca tanto pelo pioneirismo como pela audácia de produzir, já nos anos 1960, uma geografia regional histórico-crítica centrada na denúncia da problemática do desenvolvimento desigual brasileiro, sobretudo das desigualdades internas, como ele afirmaria, da região Nordeste.

Geografia, região, espaço e território na obra de Manuel Correia de Andrade

Manuel Correia de Andrade é um dos pesquisadores que teve centralidade no movimento de renovação da geografia no Brasil, desde os anos 1950, juntamente com autores estrangeiros como Pierre Monbeig e Pierre George. É, grosso modo, entre os anos 1950 e 1960, uma geografia de transição para abordagens consideradas mais radicais, com um caráter político muito forte. Uma de suas obras de destaque, internacionalmente conhecida, é A terra e o homem no Nordeste, publicada pela primeira vez em 1963.

Para Andrade (1963), a região é o conceito principal, considerando elementos da natureza e da sociedade, principalmente desta última, evidenciando aspectos fundamentais do uso da terra, da ocupação e das relações de trabalho no Nordeste brasileiro, ou seja, os sujeitos sociais, substantivando uma abordagem importante para sua época. Há ênfase para o processo histórico descrito a partir de um recorte regional, numa abordagem eminentemente areal, histórica, econômica, descritiva e crítica. O Nordeste é compreendido como uma região geográfica, revelando, desde o início da obra, a influência que tivera da geografia regional francesa substantivada por Paul Vidal de La Blache e outros pesquisadores.

A região geográfica abrange uma paisagem e sua extensão territorial, onde se entrelaçam de modo harmonioso componentes humanos e natureza. A idéia de harmonia (...) constitui o resultado 
de um longo processo de evolução, de maturação da região, onde muitas obras do homem fixaram-se, ao mesmo tempo com grande força de permanência e incorporadas sem contradições ao quadro final da ação humana sobre a natureza (Corrêa, 1987, p.28).

Assim, o Nordeste é dividido em zonas, áreas ou sub-regiões com características sociais e naturais específicas que diferenciam umas das outras como habitats e paisagens (Meio-Norte, Sertão, Litoral, Agreste e Zona da Mata). O território é compreendido como área e Estado-nação, considerado de maneira subjacente na argumentação metodológica. Os elementos da natureza destacados são os rios, a vegetação, o clima, o regime pluviométrico e o solo. As atividades sociais evidenciadas são o cultivo da cana-de-açúcar e do algodão, a criação de gado, a policultura de subsistência, a estrutura fundiária, a mão-de-obra, aspectos que podem ser observados no decorrer desta obra, por exemplo, na citação a seguir:

\begin{abstract}
A Baixada Maranhense, por exemplo, fica inteiramente inundada durante grande parte do ano, forçando os rebanhos que aí vivem a fazer grandes migrações ou a serem recolhidos a pequenas porções mais altas, durante a inundação. Os campos aí existentes, ricos em ciperáceas, lembram consideravelmente os campos de Marajó e do Baixo Amazonas. No sul do Maranhão, onde se encontram importantes cidades como Imperatriz (...) e Carolina, observamos uma vegetação típica do centro-oeste (...). É área de pecuária ultraextensiva em campo aberto (...). Estes fatos nos levam a considerar o Meio-Norte como uma área de transição entre o Nordeste, o Norte e o Centro-Oeste do País (Andrade, 1963, p.47).
\end{abstract}

Há destaque para a concentração da terra, para as técnicas produtivas e para os trabalhadores, caboclos, escravos, técnicos e assalariados, especialmente a partir do fortalecimento da agroindústria açucareira, elaborando uma geografia crítica e de denúncia das condições de trabalho e vida no espaço agrário do Nordeste brasileiro, construída a partir de referências como Pierre George, Gilberto Freyre e Caio Prado Jr.. “O algodão era por natureza uma cultura mais democrática que a cana-de-açúcar. Não só os grandes proprietários, utilizando mão-de-obra escrava e assalariada, cultivavam-no, como também pequenos proprietários, foreiros e moradores” (Idem, p.125). 
De acordo com este autor, substantivam-se regiões pecuárias, fumicultoras, algodoeiras, canavieiras, em consonância com as características naturais e sociais aí estabelecidas historicamente. A pecuária predomina em grandes propriedades, bem como o cultivo da cana-de-açúcar; o algodão ocorre nas duas situações: grandes e pequenas propriedades; o fumo em pequenos estabelecimentos. Ao mesmo tempo, estas atividades condicionam a implantação de caminhos e estradas (rotas) que influenciam, aos poucos, nas primeiras redes de circulação e comunicação no interior do Nordeste, facilitando o que Manuel Correia de Andrade denominou de ocupação horizontal (p.184), historicamente condicionada, caracterizando as diferentes regiões, áreas, zonas ou porções do Nordeste brasileiro.

Esta obra, A terra e o homem no Nordeste (1963), marca, conforme Maia (2009), na geografia agrária brasileira, uma fonte fundamental de análise para os estudos sobre a estrutura fundiária e as relações de trabalho no campo, antecedendo o processo de renovação da geografia brasileira desencadeado nos anos 1970. Nesta obra, apesar de não ser considerada de geografia crítica ou marxista, percebe-se influências de alguns pensadores que já trabalhavam com o materialismo histórico e dialético, como Caio Prado Jr.. Manuel Correia de Andrade faz, ao nosso ver, uma análise histórico-regional e, evidentemente, geográfica.

Rosa Maria Vieira Medeiros (2009), referindo-se a este livro (A terra e o homem no Nordeste), resume muito bem sua importância: "É um marco na Geografia Agrária brasileira pois traz para o debate geográfico questões relativas à propriedade da terra, às relações de trabalho, às condições de trabalho e de vida dos trabalhadores rurais, às intervenções e às ações políticas. Nesta obra, de forte impacto político, a questão agrária brasileira é despida de suas vestes falsas para ser vista de forma clara e transparente ».

Em outra obra da segunda metade dos anos 1960, Manuel Correia de Andrade (1970/1967) ratifica a compreensão de espaço geográfico definida por Max Sorre a partir da situação de um ponto ou de uma área, ou seja, de uma cidade ou região ou nação. A localização é importante, bem como a delimitação (fronteira), o acesso ao mar, a altitude, a circulação, resultando na organização do espaço, juntamente com as condições naturais. 
Outras referências importantes para ele nesta obra são: Yves Lacoste, François Perroux e Bernard Kayser. O conceito de região também é central, juntamente com o de espaço geográfico, resultando de componentes naturais e sociais. Seu enfoque é econômico, desenvolvido a partir de uma abordagem eminentemente descritiva, areal e reflexiva. Por isto, destaca o espaço econômico, resultante das ações de grandes empresas, trustes e cartéis sendo, assim, setorial e descontínuo. A organização do espaço se dá por setores e em torno de centros (pólos), com certas características econômicas, políticas e culturais, gerando, assim, as regiões (no entorno dos centros). Estas resultam, então, de processos sociais e espaciais, da regionalização e de redes de transportes e de comunicações. As redes ocorrem no interior de cada região e entre as regiões hierarquicamente organizadas.

Nestas primeiras obras de Manuel Correia de Andrade, é facilmente perceptível a influência que sofreu, diretamente, da geografia regional francesa. Ele elabora uma concepção eminentemente areal, histórica e político-econômica em virtude das características principais daquela geografia. O processo histórico é tido como um elemento explicativo indispensável para estabelecer as características de um país ou de uma região, evidenciando-se as diferentes formas de organização espacial.

Em Andrade (1971/1967), escrito logo depois de seu retorno da França, encontramos, talvez, uma de suas principais obras na qual dá centralidade ao conceito de território, ou melhor, à organização social do território. Antes e depois, seus conceitos principais são região e espaço, o que já revela aspectos das fases de sua formação e atuação como profissional. Nesta obra, Manuel Correia de Andrade evidencia as condições (geográficas, históricas, econômicas e sociais) consideradas fundamentais para o desenvolvimento e suas disparidades em distintas regiões.

Há, por este raciocínio, regiões mais ou menos desenvolvidas que caracterizam o desenvolvimento regional de certo país. "Há, assim, dentro de cada país, dentro de cada Estado, uma diferença muito grande no desenvolvimento regional” (Andrade, 1971/1967, p.32). São áreas ou zonas com determinadas características de povoamento, por exemplo, ou, de maneira mais geral, com características políticas, econômicas, culturais e geográficas, lembrando claramente o conceito de região geográfica largamente difundido a partir da geografia regional francesa, já mencionado. 
O Brasil, sucintamente, é compreendido como um território formado por várias regiões, onde certas cidades se tornam, historicamente, pólos de desenvolvimento econômico e estão ligadas através de redes hierárquicas. Raciocínio que também está presente em Andrade (1974), tanto empírica como metodologicamente. Os conceitos principais são área e região, numa abordagem areal e descritiva, de análise das desigualdades regionais. O território permanece sem alteração, isto é, corresponde ao Estado-nação, a uma área e palco dos processos sociais, como substrato e recorte espacial. Apesar do destaque, não há aprofundamento conceitual.

Em Andrade (1974) notamos um esforço feito para aplicar a teoria dos pólos de desenvolvimento para compreender os países do chamado terceiro mundo. O entendimento de que o desenvolvimento poderia se propagar teve centralidade nesta concepção que, na avaliação do autor, poderia ser utilizada parcialmente com relação à América Latina, a partir das experiências de W. Christaller, J. Boudeville, M. Rochefort, entre outros. Teorias de B. Kayser e F. Perroux também foram importantes para suas reflexões sobre o desenvolvimento desigual regionalmente configurado.

Assim, considerou cinco níveis distintos: o nacional, o macro-regional, o regional, o sub-regional e o local, ratificando sua elaboração metodológica anterior (Andrade, 1970/1967). Isto gerou classificações de áreas ou zonas distintas, caracterizadas considerando aspectos econômicos, políticos, culturais e naturais, inerentes à organização do espaço por meio de hierarquias entre os pólos de desenvolvimento. O conceito de organização espacial, juntamente com a noção de área, é central em sua argumentação. O território, desse modo, corresponde a uma área delimitada do espaço, caracterizado a partir da influência econômica dos pólos e de um procedimento classificatório de regionalização para fins de planejamento.

Assim, o Nordeste corresponde a uma região delimitada por características naturais e sociais, distinto das demais regiões brasileiras. As redes de circulação e comunicação são consideradas a partir das funções das cidades centrais em suas áreas de influência, porém, de maneira subjacente. Destaca o caráter regional dos processos estudados, ou seja, a organização histórica do espaço a partir das ações antrópicas, sobretudo econômicas. O Brasil, deste modo, é caracterizado como um mosaico regional formado por "ilhas" mais 
ou menos integradas (p.87) e organizadas hierarquicamente por meio dos pólos e das redes, gerando as chamadas regiões geoeconômicas. "Daí podemos afirmar, baseado na Teoria dos Pólos de Desenvolvimento de F. Perroux, que no Brasil observamos um pólo bastante dinâmico - São Paulo - que atrai os fluxos de todo o país e que desenvolve a região em que está situado e, nas áreas periféricas, regiões deprimidas, ora superpovoadas, ora subpovoadas” (Andrade, 1974, p.212).

Permanece, nesta obra, uma abordagem eminentemente descritiva, econômica e areal, a partir de procedimentos classificatórios inerentes às teorias dos pólos de desenvolvimento, considerando, assim, características naturais e antrópicas, bem como desigualdades internas e redes de circulação. Há destaque, além do conceito de região, para a organização do espaço, incremento importante em sua elaboração teórico-metodológica da década de 1970.

Abordagem que perdura visivelmente em outras obras posteriores, como na intitulada O planejamento regional e o problema agrário no Brasil (1976), na qual a região corresponde à categoria de análise principal, compreendida como resultado das ações dos homens organizando o espaço a partir das condições naturais. Assim, é entendida como uma entidade dinâmica, ocupada e organizada historicamente.

O espaço assume um papel subsidiário, utilizado, sobretudo, para descrever aspectos históricos da questão agrária brasileira, evidenciando-se espaços econômicos e políticoadministrativos a partir de obras de autores como Celso Furtado e Caio Prado Júnior. A organização do espaço resulta nas regiões, a partir dos contrastes internos. Daí, reconhece a existência de sub-regiões ligadas por redes, como a Zona da Mata e o Agreste, divisões/compartimentos do Nordeste brasileiro. As regiões e sub-regiões revelam as características naturais e os diferentes níveis de desenvolvimento, bem como as distintas formas de ocupação, ou seja, os contrastes internos de cada país e região.

Teorização que é aprofundada nos anos 1980 e socializada em Andrade (1984), por exemplo, ao estudar o Estado e suas implicações na organização do espaço. É um texto de geografia política e econômica, no qual Manuel Correia de Andrade faz uma crítica a geografia política clássica, propugnando em favor da geografia crítica para desvendar e explicar as classes sociais, a atuação do Estado em diferentes instâncias e o espaço 
produzido socialmente. Este, é o conceito principal em Andrade (1984): “Ao se estudar o espaço e sua produção, deve-se levar em conta, conscientemente, que o espaço produzido é o resultado da ação do homem transformando em função de suas necessidades, o meio natural” (p.16). O espaço, nesta concepção, é transformado histórica e socialmente, por meio da tecnologia, do capital e da atuação do Estado; produto das relações sociedadenatureza.

\begin{abstract}
Implantada uma forma de utilização da terra e, conseqüentemente, um tipo de espaço, este nunca se torna definitivo, estático; com a evolução da economia e da sociedade, outras utilizações vão sendo dadas à terra, ora visando a modificar a produção, ora visando a acelerar a atividade produtiva, modificações essas que se exteriorizam no tipo do espaço produzido. Por isto a produção do espaço nunca fica perfeita e acabada, havendo uma constante reprodução da mesma (Andrade, 1984, p.17).
\end{abstract}

Deste modo, o espaço é construído de maneira processual e dinâmica, constantemente reformulado e envolvendo, necessariamente, os órgãos do poder e as classes sociais dominantes e dominadas. Isto significa, para o autor, que a produção do espaço constitui uma contínua luta entre os grupos sociais, também envolvendo as forças produtivas. O espaço é, ao mesmo tempo, heterogêneo, em virtude das ações do Estado e dos agentes do capital que organizam o território de acordo com seus interesses; há um “(...) jogo de interesses, de pressões e de poder existentes entre classes e grupos sociais” (Idem, p.19), que fazem parte da reprodução do Modo Capitalista de Produção.

Já a obra Geografia: ciência da sociedade (2006/1987), revela uma fase de síntese teórico-metodológica resultante, certamente, de suas reflexões teóricas, conceituais e empíricas. É uma obra basilar da renovação da geografia produzida no Brasil e marca um salto qualitativo na produção intelectual de Manuel Correia de Andrade. Isto não significa dizer que ele não estudara estas questões anteriormente. Pelo contrário, a publicação do livro em 1987 é produto de uma trajetória de pesquisas realizadas até então.

Em Andrade (2006/1987), notamos claramente uma abordagem espaço-temporal de aspectos fundamentais da história e epistemologia da geografia, subsidiando decididamente o fortalecimento da geografia como uma ciência social. Esta é a questão ou pelo menos uma das principais desta obra. A geografia é a ciência que estuda a organização social do Geo UERJ - Ano 12, nº. 21, v. 2, $2^{\circ}$ semestre de 2010. www.geouerj.uerj.br/ojs ISSN 1981-9021 
espaço como processualidade interdisciplinar ou, mais precisamente, as intervenções que a sociedade executa na natureza, “devendo indicar caminhos para a sociedade” (Idem, p.30).

Assim, organiza esta obra descrevendo e analisando a substantivação da geografia desde a Antiguidade, passando pela Idade Média, pelo Renascimento, pela Geografia dos Tempos Modernos, pela Contemporânea até a Geografia Clássica e a institucionalização da ciência geográfica no Brasil, análise na qual o conceito principal é o espaço geográfico, evidenciando autores, obras, acontecimentos e processos de diferentes períodos e países que influenciaram direta e indiretamente na construção do pensamento geográfico. Na oportunidade, identificara quatro grandes correntes teórico-metodológicas inerentes à geografia do período entre os anos 1960 e 1980: i) a teórico-quantitativista; ii) a do comportamento e percepção; iii) a ecologista e, iv) a radical, sobretudo marxista. Todas evidentes no Brasil e em outros países, a partir de determinados conceitos, tais como região e regionalização, espaço, lugar, paisagem e território, destacados de acordo com as premissas básicas de cada corrente ou argumentação teórico-metodológica.

Classificação que, grosso modo, encontra-se com a feita por Bray (2010), ao se referir às escolas geográficas em São Paulo e no Brasil entre 1934 e 1976, identificando a positivista/funcionalista (sob influência do empirismo elaborado na França), a neopositivista (sob influência norte-americana e, sobretudo neokantiana) e a materialista histórica (a partir das obras de Pierre George e Yves Lacoste).

Cabe destacar, ainda, o caráter político desta obra de Manuel Correia de Andrade, revelado especialmente a partir dos temas tratados nos capítulos 10 e 11, intitulados, respectivamente, Geografia e ação, e A Geografia e a problemática do mundo atual, evidenciado aspectos centrais do que estamos denominando de uma concepção operativa, isto é, que possa gerar subsídios para a atuação política do pesquisador. Já o conceito de território permanece em um nível bastante subsidiário, compreendido como área e/ou Estado-nação.

Identificamos seu caráter de cidadão e político em Geopolítica do Brasil (1989), obra que também revela a amplitude temática de seus estudos e publicações para além da questão agrária: “(...) o acadêmico, o cientista, antes de ser acadêmico ou cientista é cidadão e, como cidadão, tem compromissos políticos e sociais com a sociedade e o Estado 
onde vive e trabalha” (p.8). Parece que esta identificação com as causas sociais sempre esteve presente em seu trabalho como professor e pesquisador, aspecto também evidenciado por Medeiros (2009).

Além disto, em Andrade (1989), notamos uma rarefação do caráter regional-areal em sua abordagem geográfica, ou seja, há ênfase para os processos históricos e relacionaisespaciais, e a região assume, ao nosso ver, um caráter subsidiário. Caracteriza-se como um texto didático e reflexivo sobre determinados aspectos da geopolítica do Brasil nos períodos Colonial, Imperial e Republicano. O território, nesta obra, aparece como recorte espacial apropriado e dominado militar e estrategicamente, como uma parcela ou porção do espaço. Já o espaço é um conceito mais amplo, vinculado à organização societal, ou seja, envolvendo relações de poder, efetivadas especialmente entre diferentes nações.

No início dos anos 1990, em Andrade (1991), o território aparece, novamente, como Estado-nação, embora qualificado a partir de relações de poder mais amplas que extrapolam a atuação do Estado e envolvem os movimentos sociais, principalmente os populares, conhecidos como revoltas internas que aconteceram no Brasil. De modo geral, descreve e faz uma análise histórica de aspectos importantes de alguns conflitos de classe ocorridos neste país. Pode ser caracterizado como um estudo de geografia política, ou melhor, da política efetivada no Brasil, sobretudo no período pós-Independência, mostrando processos centrais da formação do Estado brasileiro. Isto revela, juntamente com outros aspectos de outras obras, permanências significativas em seu pensamento e abordagem, bem como na concepção de região e de território: são formações areais substantivadas a partir da atuação do Estado e dos grupos oligárquicos regionalmente estruturados.

Uma reflexão mais significativa sobre o conceito de território ocorre nos anos 199394, descrita em Andrade (1994). O território assume centralidade e é compreendido a partir das idéias de domínio, de poder e de gestão de certa área, seja por parte do Estado, seja por parte de grandes empresas. O destaque é para a formação e atuação do Estado brasileiro, numa concepção eminentemente política e econômica. Não há aprofundamento sobres os conceitos utilizados. 
Já Andrade (1995) incorpora o conceito de território no bojo de um movimento mais amplo, originado, principalmente, na França e na Itália, mas disperso por outros países, como a Suíça e os EUA. Para Manuel Correia de Andrade, o conceito de território é inerente à idéia de domínio ou gestão de determinada área: “Assim, deve-se ligar sempre a idéia de território à idéia de poder, quer se faça referência ao poder público, estatal, quer ao poder das grandes empresas que estendem os seus tentáculos por grandes áreas territoriais, ignorando as fronteiras políticas” (Andrade, 1995, p.19). Enfatiza, em sua abordagem, novamente, as forças políticas e econômicas na constituição do território. Na dinâmica econômica, reconhece o rompimento das fronteiras pela atuação de grandes empresas, como trabalhara anteriormente (1994).

No entanto, Manuel Correia de Andrade não aprofunda o estudo do conceito de território e nem mesmo o de territorialidade, mantendo certa fidelidade aos conceitos de espaço e região, centrais em sua trajetória como pesquisador. O território é entendido como produto da ação e gestão do Estado, lançando mão do conceito de área para tentar revelar a importância desta atuação na formação do Brasil enquanto Estado nacional.

Seu entendimento de territorialidade pode ser assim resumido: "Admitimos que a expressão territorialidade possa vir a ser encarada tanto como o que se encontra no território, estando sujeita à sua gestão, como, ao mesmo tempo, o processo subjetivo de conscientização da população de fazer parte de um território, de integrar-se em um Estado” (Andrade, 1995, p.20). A territorialidade é concebida como recursos e/ou elementos, como o povo, presentes em certa área, e como sentimento de pertencimento a um Estado-Nação.

A territorialidade, na sua compreensão, dá-se com a formação do Estado, sendo regionalizada histórica e diferentemente. Em sua descrição e análise de aspectos da formação do Brasil, entre os séculos XVI e XX, há características da substantivação do território, revelando relações de poder, de apropriação, dominação e gestão. Ao tratar, por exemplo, da mobilidade de paulistas para escravizar indígenas do Sul do Brasil, e de pernambucanos e baianos no Nordeste, ele revela a efetivação de redes de circulação, sempre fundamentais na formação de certo território compreendido, em concepções renovadas, conciliando-se a relação área-rede. Sua abordagem, nesta obra, é eminentemente 
areal e histórica, porém, reconhecendo a importância das relações de poder e das redes de circulação e comunicação que interligam as regiões brasileiras.

Há uma compreensão predominante do poder concretizado a partir das ações do Estado, no entanto, ele também reconhece o poder presente em outras relações sociais, o que significa um avanço considerável, ampliando a leitura e a compreensão do território combinando aspectos materiais e imateriais.

Enfim, Manuel Correia de Andrade tenta acompanhar mudanças que acontecem no nível do pensamento e no real, gerando uma teorização geográfica com um caráter político bastante expressivo desde o final dos anos 1960, conforme evidenciamos no quadro a seguir. Isto revela, metodologicamente, o quanto é complexo e delicado estudar a construção do pensamento e do conhecimento, pois se trata de um processo histórico e relacional, constituído por indivíduos que vivem em sociedade, pensam, criam, têm sonhos, necessidades e aspirações políticas, relações e processos dificilmente apreendidos somente a partir da leitura de suas obras escritas.

É uma situação empolgante, porém, de grande responsabilidade para quem se propõe fazer pesquisas desta natureza. O pensamento e o conhecimento envolvem aspectos da própria ciência estudada, de outras áreas do conhecimento, da filosofia, da política, da ideologia etc., inerentes a cada relação espaço-tempo vivida por cada pesquisador estudado. Isto é, corresponde, também, a um processo histórico e relacional, condicionado por fatores e elementos materiais e imateriais/ideais num único movimento de reprodução do pensamento, do conhecimento, da natureza e da sociedade. Como alertara coerentemente Quaini (2003), a história e a identidade são atributos tanto das pessoas como das disciplinas científicas e ganham seus contornos e significados quando estudados meticulosamente. 
Principais temas, conceitos e concepções elaboradas no período estudado (1963-1995)

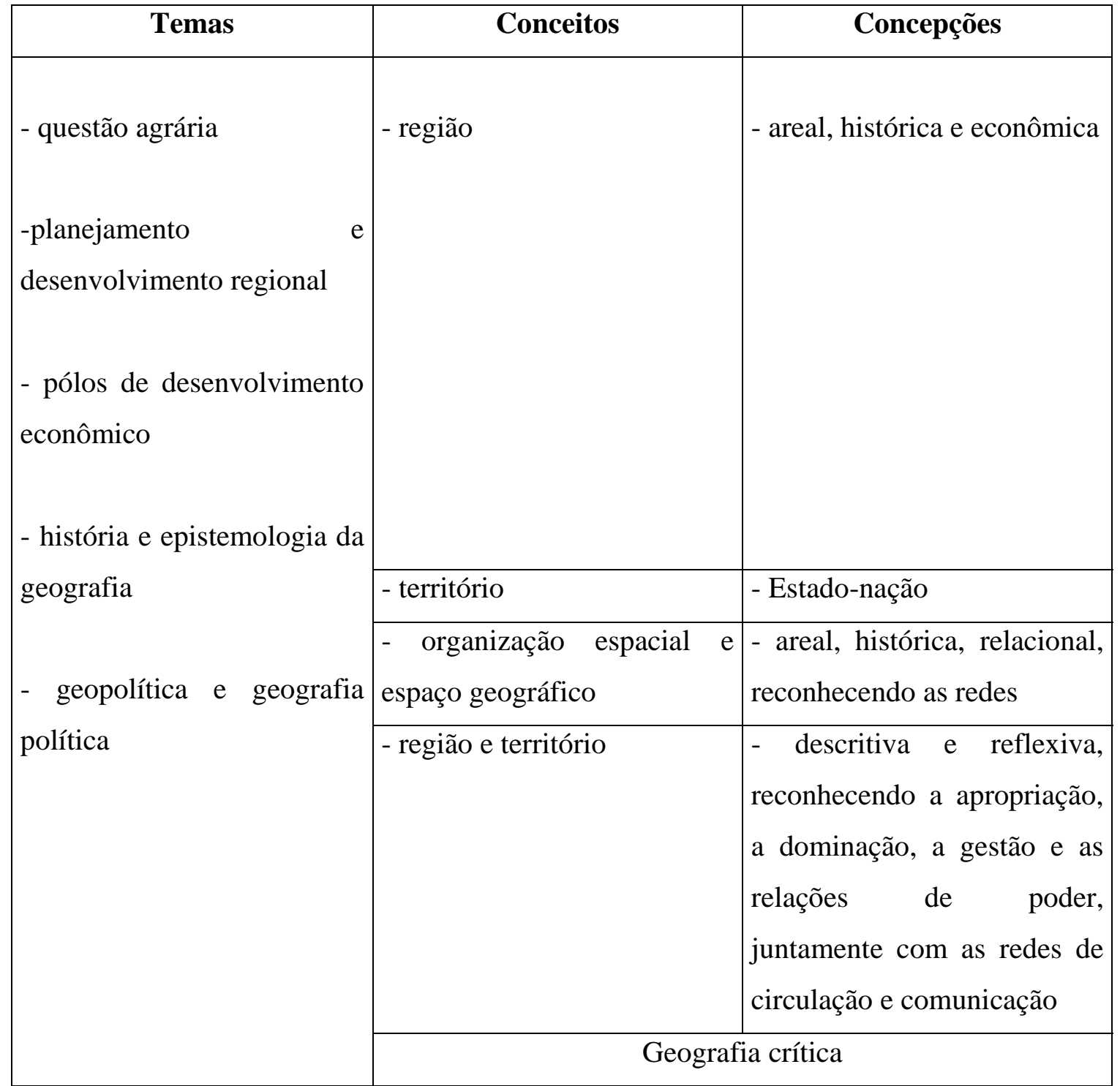

Fonte: obras selecionadas e analisadas neste texto; elaboração nossa, 2010.

Acreditamos que esta é uma boa forma para encerrarmos este texto, isto é, afirmando que a obra do Manuel Correia de Andrade é substantiva e contribui de maneira efetiva e sistemática para a renovação da geografia no Brasil, especialmente para a substantivação de uma perspectiva crítica e reflexiva, uma geografia de denúncia e propositiva em relação à formação histórica brasileira centrada num processo concentrador e centralizador, 
contribuindo para desvendar e explicar jogos de poder e controle do povo e do território brasileiro.

Considerações finais

Questão agrária, planejamento, desenvolvimento regional, concentração da terra, subordinação dos trabalhadores rurais, técnicas produtivas, oligarquias regionais, pólos de desenvolvimento, epistemologia, geopolítica, entre outros, todos temas selecionados, compreendidos e explicados por Manuel Correia de Andrade, ao longo de uma carreira docente e política influenciada por princípios da geografia regional francesa e de outras perspectivas mais recentes, vinculadas ao materialismo histórico e dialético. Abordagens e concepções elaboradas a partir de conceitos como os de região, organização do espaço, espaço produzido e território, sempre ampliados e atualizados para tentar compreender os processos ligados à formação do povo e do território brasileiro.

De uma abordagem eminentemente areal, descritiva, histórica e econômica, avança ampliando-a com os processos políticos e geopolíticos, elaborando uma concepção reflexiva e propositiva da apropriação, dominação e gestão do espaço e do território, explicando os jogos de poder, a subordinação, sempre em favor do povo brasileiro, como ele próprio afirmaria. Cumpriu um papel decisivo na revisão e atualização da geografia brasileira, bem como na denúncia da problemática do desenvolvimento desigual e na proposição de ações e planos tentando contribuir para amenizar as desigualdades regionais.

Referências

ANDRADE, Manuel Correia de. A terra e o homem no Nordeste. São Paulo: Brasiliense, 1963.

ANDRADE, Manuel Correia de. Espaço, polarização e desenvolvimento. São Paulo: Brasiliense, 1970 (1967).

ANDRADE, Manuel Correia de. Geografia, região e desenvolvimento. São Paulo: Brasiliense, 1971 (1967).

ANDRADE, Manuel Correia de. Nordeste, espaço e tempo. Petrópolis: Vozes, 1970.

ANDRADE, Manuel Correia de. Geografia econômica. São Paulo: Atlas, 1973.

ANDRADE, Manuel Correia de. Cidade e campo no Brasil. São Paulo: Brasiliense, 1974.

ANDRADE, Manuel Correia de. O planejamento regional e o problema agrário no Brasil. São Paulo: Hucitec, 1976. 
ANDRADE, Manoel Correia de. Agricultura \& Capitalismo. São Paulo: Ciências Humanas, 1979.

ANDRADE, Manuel Correia de. Estado, capital e industrialização no Nordeste. Rio de Janeiro: Zahar, 1981.

ANDRADE, Manuel Correia de. Poder político e produção do espaço. Recife: Massangana, 1984.

ANDRADE, Manuel Correia de. Geografia: ciência da sociedade. Recife: Ed. Universitária da UFPE, 2006 (1987).

ANDRADE, Manuel Correia de. Geopolítica do Brasil. São Paulo: Ática, 1989.

ANDRADE, Manuel Correia de. Caminhos e descaminhos da Geografia. Campinas, São Paulo: Papirus, 1989a.

ANDRADE, Manuel Correia de. O povo e o poder. Belo Horizonte: Oficina do Livro, 1991.

ANDRADE, Manuel Correia de. Territorialidades, desterritorialidades, novas territorialidades: os limites do poder nacional e do poder local. In: SANTOS, Milton; SOUZA, Maria; SILVEIRA, Maria (Org.). Território: globalização e fragmentação. São Paulo: Hucitec/ANPUR, 1994.p.213-220.

ANDRADE, Manuel Correia de. A questão do território no Brasil. São Paulo: Hucitec, 1995.

BOUDEVILLE, Jacques. Les Programmes Économiques. Paris: Universitaires de France, 1963.

BRAY, Silvio C. As escolas geográficas em São Paulo e no Brasil: 1934 e 1976 (uma tentativa de classificação). In: SPOSITO, E. e SANT’ANNA, J. (Org.). Uma geografia em movimento. São Paulo: Expressão Popular, 2010.p.135-142.

CELANT, Attilio. Nuova città e nuova campagna. In: CELANT, A. Nuova città, nuova campagna. L'Italia nella transizione. Bologne: Patrón, 1988. p.1-50.

CLAVAL, Paul. L'evoluzione storica della geografia umana. Milano: Angeli, 1972.

CORRÊA, Roberto Lobato. Região e organização espacial. SP: Ática, 1987.

DEMATTEIS, Giuseppe. La nascita dell'indirizzo marxista nella ricerca geografica italiana. In: La ricerca geografica in Italia 1960-80. Varese: Ask Edizioni, 1980. p.781792.

DEMATTEIS, Giuseppe. Geografia democrática, território e desenvolvimento local, Formação, Presidente Prudente, n.12, v.2, 2005, p.11-26.

GEORGE, Pierre. Questions de géographie de la population. Paris: PUF, 1959.

HARVEY, David. A reinvenção da geografia - uma entrevista com os editores da New Left Review. In: HARVEY, David. A produção capitalista do espaço. São Paulo: Annablume, 2005. p.15-40.

LACOSTE, Yves. A Geografia. In: CHATELET, François. História da filosofia. A filosofia das Ciências Sociais. Vol.7. Rio de Janeiro: Zahar, 1974.

MAIA, Doralice Sátyro. O pensamento de Manoel Correia de Andrade e a sua obra A terra e o homem no Nordeste, Scripta Nova, Barcelona, Vol. XIII, núm. 288, 15 de abril de 2009.

MEDEIROS, Rosa Maria Vieira. Manuel Correia de Andrade e a questão agrária Brasileira, Scripta Nova, Barcelona, Vol. XIII, núm. 288, 15 de abril de 2009. 
QUAINI Massimo. Costruire 'geostorie' - un programma di ricerca per i giovani geografi, Geostorie, anno 11, n.1, 2003, Roma, p.3-15.

RAFFESTIN, Claude. Entrevista, Formação, Presidente Prudente, n.15, vol.1, 2008, p.1-5. SAQUET, Marcos. Proposições para estudos territoriais, Geographia, Rio de Janeiro, n.15, 2006, p.71-85.

SAQUET, Marcos. Abordagens e concepções de território. São Paulo: Expressão Popular, 2007.

SILVA, Lenyra Rique da. Revisão da questão agrária brasileira a partir da ótica de Manuel Correia. In: FELIPE, José L. (Org.). Manoel Correia de Andrade: o geógrafo e o cidadão. Natal: UFRN, 1995. p.153-172.

Enviado para publicação em novembro de 2010.

Aceito para publicação em dezembro de 2010. 